\title{
PENGENALAN LETAK POSYANDU TERDEKAT DIKELURAHAN PISANGAN DENGAN MANAJEMEN PEMASARAN REVOLUSI 4.0 UNTUK MENINGKATKAN PENGETAHUAN MASYARAKAT LETAK DAN FUNGSI POSYANDU TERDEKAT PADA KELURAHAN PISANGAN
}

\author{
Veta Lidya Delimah Pasaribu, Sulaiman, Sutiman, Thaharudin, Bambang Y. Purnomo. \\ Program Studi Manajemen \\ Universitas Pamulang \\ Email : dosen01889@umpam.ac.id
}

\begin{abstract}
Community Service (PKM) is an integral part of the Tri Dharma of Higher Education which in its implementation is inseparable from the other two dharmas, and involves all academics: lecturers, students, education staff and alumni. Through PKM the academic community can be present in the midst of the community. Seeing the location of the campus which is not far from the location of Pisangan Village, East Ciputat District, South Tangerang, it has become an obligation for the University of Pamulang (Unpam) to participate in helping various problems faced by the community both near and far. Marketing Management, particularly financial management, is related to how to find out about fund management systematically, so that financial management is not only the mastery of a collection of knowledge but also a processinvention. The problem that arises is the absence of adequate learning media to explain a concept. Effective learning. However, most schools still feel the lack of facilities and infrastructure. information is still quite difficult to obtain. This will make it difficult for the community to understand the concept, so extension workers must be creative and innovative. PKM with the title: "The introduction of the location of the nearest posyandu in the Pisangan village with the marketing management of Revolution 4.0 to increase public knowledge of the location and function of the nearest posyandu in the village of Pisangan" in general went smoothly and in an orderly manner. the public was enthusiastic in listening to the explanation of the material provided. The enthusiasm of the residents continued when the questions and answers surrounding the demonstration. This PkM activity was considered effective because the level of community interest was quite high in the knowledge of Pisangan Village.
\end{abstract}

Keywords: Posyandu, revolution 4.0, Marketing Management 


\begin{abstract}
Abstrak
Pengabdian Kepada Masyarakat (PKM) merupakan bagian integral dari Tri Dharma Perguruan Tinggi yang dalam pelaksanaannya tidak terlepas dari dua dharma yang lainnya, serta melibatkan segenap sivitas akademika: dosen, mahasiswa, tenaga kependidikan serta alumni. Melalui PKM sivitas akademik dapat hadir di tengah- tengah masyarakat. Melihat lokasi kampus yang tidak jauh dengan lokasi Kelurahan Pisangan Kecamatan ciputat timur, Tangerang Selatan, maka sudah menjadi kewajiban bagi Universitas Pamulang (Unpam) untuk ikut serta membantu berbagai persoalan yang dihadapi masyarakat baik yang dekat maupun yang jauh. Ilmu Manejemen Pemasaran khususnya Pengelolaan keuangan berkaitan dengan cara mencari tahu tentang pengelolaan dana secara sistematis, sehingga Manajemen keuangan bukan hanya penguasaan kumpulan pengetahuan saja tetapi juga merupakan proses penemuan. Permasalahan yang timbul yaitu tidak adanya media pembelajaran yang memadai untuk menjelaskan suatu konsep. Pembelajaran yang efektif . Namun kebanyakan sekolah masih merasakan kurangnya sarana dan prasarana tersebut. informasi masih cukup sulit didapatkan. Hal ini akan mempersulit masyrakat dalam memahami konsep, jadi penyuluh harus kreatif dan inovatif. PKM dengan judul: "Pengenalan letak posyandu terdekat dikelurahan pisangan dengan manajemen pemasaran revolusi 4.0 untuk meningkatkan pengetahuan masyarakat letak dan fungsi posyandu terdekat pada kelurahaan pisangan" secara umum berjalan dengan lancar dan tertib. masyarakat antusias dalam menyimak penjelasan materi yang diberikan. Antusiasme warga pun berlanjut saat tanya jawab seputar peragaan. Kegiatan $\mathrm{PkM}$ ini dinilai berjalan efektif karena tingkat ketertarikan warga cukup tinggi terhadap pengetahuan Kelurahan Pisangan.
\end{abstract}

Kata Kunci: Posyandu , revolusi 4.0, Manajemen Pemasaran

\title{
A. PENDAHULUAN
}

Dewasa ini sistem teknologi tepat guna sangat berperan dalam kehidupan manusia saat ini, dimana pemanfaatan sumber-sumber daya yang ada dapat dikelola dengan baik dan efisien. Sehingga masyarakat dapat mengidentifikasi sedini mungkin masalah- masalah yang dihadapi dalam kehidupan sehari-hari, baik itu pemerintah, pengusaha, perguruan tinggi, petani, home industri dan lain sebagainya. Sehingga pada tahun 1998 pemerintah mendirikan Pos Pelayanan Teknologi Pedesaan (Kelurahan Pisangan) melalui menteri dalam negeri. Pada saat itu Kelurahan Pisangandes mengintruksikan para gubenur, bupati/wali kota dan camat di seluruh Indonesia utuk mensosialisasikan dan mengoprasionalisasikan Kelurahan Pisangan 
dengan cara memberikan penyuluhan, pengarahan, bimbingan dan pengawasan terhadap pelaksanaan Kelurahan Pisangan.

Dalam perjalanan Kelurahan Pisangan hingga tahun 2010 melalui instruksi tersebut diperkuat oleh Peraturan Menteri Dalam Negari No. 20 tahun 2010 tentang pemberdayaan masyarakat melalui pengerlolan Teknologi Tepat Guna (TTG) agar terjadi efisiensi, efektivitas, dan sinergi pembinaan antara pemerintah pusat, pemerintah daerah, dan masyarakat sehingga dari tingkat kecamatan dibentuklah Pos Pelayanan Teknologi Tepat Guna (Kelurahan Pisangan) yang bertugas memberikan pelayanan teknis, informasi, promosi, dan orientasi TTG kepada masyarakat. Untuk memujudkan program tersebut Kelurahan Pisangan tingkat Kota dan Kecamatan se-Indonesia memerlukan sumber daya manusia dan orang yang ahli di bidang keuangan yang berkompeten di bidangnya masing-masing, agar program yang sudah dicanangkan oleh kementerian dalam negeri dapat terwujud dan tepat sasaran. Sumber daya manusia yang berkompeten dapat mempercepat pertumbuhan bangsa, agar menjadi sumber daya yang maju dan produktif penduduk harus mempunyai kualitas yang memadai sehingga dapat menjadi modal pembangunan yang efektif. Masalah yang dihadapi di Indonesia saat ini adalah masih banyaknya sumber daya manusia Indonesia yang masih bekerja tidak sesuai dengan kompetensi dan bidangnya sehingga dalam menjalankan tugasnya masih jauh dari standar pekerjaannya sehingga hasil dari produktivitasnya tidak efektif dan efisien.

Dengan majunya dunia teknologi dan sistem informasi saat ini seyoganya dapat dimanfaatkan dengan baik oleh masyarakat Indonesia untuk meningkatkan daya saing terutama meningkatkan usaha mikro, usaha kecil dan menengah (UMKM). Diharapkan Melalui Kelurahan Pisangan Kecamatan pemanfaatan teknologi dan informasi tepat guna dapat meningkatkan kompetensi masyarkat dalam pesaingan pasar bebas dimana saat ini sudah memasuki revolusi Industri 4.0. Sehingga kehadiran Kelurahan Pisangan ditingkat Kecamatan dapat membantu mempercepat peningkatan kompetensi dan pengetahuan teknologi serta informasi untuk bersaing dalam industri 4.0.

Sasaran yang ingin di capai melalui program teknologi tepat guna (TTG) adalah agar teknologi yang digunakan sesuai dengan kebutuhan masyarakat, dapat menjawab permasalahan masyarakat, tidak merusak lingkungan dan dapat dimanfaatkan oleh masyarakat secara mudah serta menghasilkan nilai tambah dari aspek ekonomi dan aspek lingkungannya. Sehingga dengan bersenergi dengan Kelurahan Pisangan Kecamatan diharapkan masyarkat baik perseorangan, lembaga pemerintah/swasta dapat menghasilkan sebuah produk yang ramah lingkungan dan tepat guna.

\section{B. METODE PELAKSANAAN KEGIATAN}

Metode kegiatan yang digunakan kepada pengunjung adalah dengan memberikan penjelasan materi teori terlebih dahulu baru kemudian peragaan. Berikut ini adalah tahapan kegiatan yang dilakukan:1). Tahap Persiapan Adapun tahap-tahap yang dilakukan dalam kegiatan ini meliputi: Survei awal,Pada tahap ini dilakukan survei ke lokasi kecamatan ciputat timur, Fiksasi Jadwal Pada tahap ini dilakukan penentuan waktu kegiatan, Persiapan Materi Kegiatan Pada tahap ini dilakukan penyusunanbahan/materi kegiatan yang meliputi: slide powerpoint dan handout, Persiapan Peragaan Pada tahap ini dilakukan persiapan alat dan bahan untuk peragaan .2). Tahap Pelaksanaan Kegiatan.Untuk melaksanakan kegiatan ini 
digunakan 3 metode, yaitu: Metode Penjelasan Teori Sederhana Memberikan penjelasan singkat dan sederhana konsep, Metode Peragaan Melakukan peragaan insitu, Diskusi Melakukan diskusi dengan stake holder Kelurahan Pisangan untuk membuka wawasan.

\section{HASIL DAN PEMBAHASAN}

Promosi adalah merupakan kegiatan yang ditujukan untuk mempengaruhi konsumen agar mereka dapat menjadi kenal akan produk yang ditawarkan oleh perusahaan kepada mereka dan kemudian mereka menjadi senang lalu membeli produk tersebut. Menurut Philip Kotler, promosi atau komunikasi pemasaran terdiri atas empat sarana atau alat yang penting yaitu periklanan (advertising), publisitas (publicity), dan penjualan pribadi (personal selling). Periklanan (advertising) Iklan atau advertising adalah setiap bentuk komunikasi nonpersonal mengenai suatu organisasi, produk, servis, atau ide yang dibayar oleh satu sponsor yang diketahui. Iklan merupakan salah satu bentuk promosi yang paling dikenal dan paling banyak dibahas orang, hal ini memungkinkan karena daya jangkauannya yang luas.Iklan juga menjadi instrumen promosi yang sangat penting, khususnya bagi perusahaan yang memproduksi barang atau jasa yang ditujukan kepada masyarakat luas. Berikut ini ada beberapa media periklanan yang digunakan oleh kelurahan pisangan :

1. Melakukan kerja sama dengan pengusaha atau rekan dalam pemasangan iklan, seperti mengirimkan penawaran produk kepada para donatur atau memberikan potongan harga bagi pembelian produk yang dihasilkan para santri.

2. Memperkenalkan produk dan usaha melalui beberapa media gratis. Hal ini bertujuan untuk membantu pencarian para konsumen mengenai produk apa saja yang ditawarkan, seperti publikasi melalui internet (media sosial) dengan melibatkan lingkungan yang berada di sekitar usaha.

Publisitas merupakan cara yang biasa digunakan juga oleh pengusaha untuk membentuk pengaruh secara tidak langsung kepada konsumen agar mereka menjadi tahu dan menyenangi produk yang dipasarkannya. Cara ini dilakukan dengan cara membuat berita tentang produk atau perusahaan yang menghasilkan produk tersebut di massa media, misalnya saja berita di surat kabar, berita di radio atau televisi maupun majalah tertentu dan sebagainya. Selain menggunakan acuan yang terdapat dalam marketing mix, seorang marketing (tenaga pemasaran) mempunyai strategi tersendiri dalam pemasaran produk Kelurahan Pisangan, yakni dengan cara Pendekatan Emosional Marketing biasanya mencari calon donatur baru atau meningkatkan produktifitas donatur lama.Hal ini biasanya dilakukan seperti sering mengajak komunikasi donatur atau calon donatur, atau dengan pemberian sesuatu yang bisa menimbulkan simpati dari donatur

\section{KESIMPULAN DAN SARAN}

\section{Kesimpulan}

Kegiatan Pengabdian Kepada Masyarakat (PKM) dengan judul : "Pengenalan letak posyandu terdekat dikelurahan pisangan dengan manajemen pemasaran revolusi 4.0 untuk meningkatkan pengetahuan masyarakat letak dan fungsi posyandu terdekat pada kelurahaan pisangan" secara umum berjalan dengan lancar dan tertib. Masyarakatantusias dalam menyimak penjelasan materi teori dan peragaan yang diberikan. Antusiasme masyrakat pun 
berlanjut saat sesi tanya jawab seputar peragaan dan saat diadakan lomba pembuatan harmonika sederhana. Kegiatan PKM ini dinilai berjalan efektif karena tingkat ketertarikan masyarakatcukup tinggi terhadap pembelajaran pemasarn.Permasalahan lain yang timbul yaitu tidak adanya media pembelajaran yang memadai untuk menjelaskan suatu konsep di luar praktikum. Hal ini akan mempersulit masyarakatdalam memahami konsep sehingga tak jarang masyarakat memahami di luar konsep yang sebetulnya. Jadi dosen harus kreatif dan inovatif

\section{Saran}

Dengan diselenggarakan kegiatan PKM ini diharapkan dapat meningkatkan etos kerja yang solid dan kinerja yang optimal dosen di Prodi Manajemen. Selanjutnya tantangan dari Pengurus Kelurahan Pisangan Kecamatan ciputat timur agar para dosen bisa memberikan dan memberikan semangat untuk pelatihan Hidroponik yang selama ini sudah di dapat dari narasumber lain namun kurang berjalan. Sehingga para dosen diharapkan bisa belajar dan memberikan materi tersebut dalam PKM yang akan dating.

\section{DAFTAR PUSTAKA}

Ainsworth, M. (2002). Managing Performance, Managing People: Understanding and Improving Team Performance, Frenchs Forest: Pearson Education.

Eko, S. (2014), Manajemen Pengembangan Sumber Daya Manusia, Jakarta: Ardadizya Jaya.

Ferdinand, A. (2006), Metode Penelitian Manajemen, Semarang: AGF Books.

Hollyforde \& Whiddett, (2003), The Motivation Handbook, Mumbai: Jaico Publishing House.

K. Hoy, Wayne \& Cecil G. Miskel, (2005), Educational Administration Theory, Research and Practice, New York: Mc Graw Hill.

Mulyasa, E., (2011), Manajemen Berbasis Sekolah Konsep, Strategi dan Implementasi, Bandung: PT. Remaja Rosdakarya Offset.

Sanjaya, W. (2013), Strategi Pembelajaran Berorientasi Standar Proses Pendidikan, Jakarta: Kencana Prenadamedia Group.

Sekaran, U. (2006) Research Methods For Business, Jakarta: Salemba Empat.

Sugiyono. (2002), Metode Penelitian Administrasi, Bandung: Alfabeta.

Sugiyono. (2009), Metode Penelitian Bisnis Pendekatan Kuantitatif, Kualitatif dan R\&D, Bandung: Alfabeta CV.

Suharsaputra, U. (2013), Administrasi Pendidikan, Bandung: PT. Refika Aditama.

Pasaribu, V. L. D., Agrasadya, A., Shabrina, N., \& Krisnaldy, K. (2020). Menjadi Enterpreneur Muda Yang Memiliki Jiwa Leadership Untuk Menghadapi Masa Depan. Abdi Laksana, 1(1). 
Pasaribu, V. L. D., Elburdah, R. P., Sudarso, E., \& Fauziah, G. (2020). Penggunaan Manajemen Waktu Terhadap Peningkatan Prestasi Belajar Di Smp Araisiyah. Jurnal ABDIMAS, 1(1).

Pasaribu, V. L. D., Susanti, F., \& Hartuti, E. T. K. (2019). Memotivasi Siswa Dan Siswi Smk Letris Indonesia Di Dalam Menentukan Pilihan Untuk Melanjutkan Pendidikan Atau Bekerja Setelah Lulus Sekolah. Jurnal Pengabdian Dharma Laksana, 1(2), 161-172 